\title{
Análisis dogmático del elemento típico de la "relación funcional" en el delito de peculado: ¿qué se entiende por competencia funcional del autor?
}

\author{
Dogmatic analysis of the typical element of the "functional relationship" in the crime of embezzlement: what is understood by \\ functional competence of the perpetrator?
}

Análise dogmática do elemento típico da "relação funcional" no crime de peculato: o que se entende por competência funcional do perpetrador?

\section{ARTÍCULO ORIGINAL}

\section{Valentín Soto Llerena \\ vsotol@,unp.edu.pe \\ https://orcid.org/0000-0003-4786-5557 \\ Universidad Nacional de Piura, Piura - Perú}

Recibido 05 de Febrero 2021 | Arbitrado y aceptado 19 de Abril 2021 | Publicado 28 de Julio 2021

\section{RESUMEN}

1. Análisis dogmático del delito de peculado, 1.1. Modalidades delictivas: peculado por apropiación y peculado por utilización, $\mathbf{1 . 2}$. Los elementos materiales, 2. El delito de peculado como delito de infracción de deber, 3. El elemento típico de la relación funcional: el vínculo funcional por razón de su cargo, 4. La relación funcional de hecho: ¿el funcionario de facto mantiene la relación funcional con los caudales y efectos?, $\mathbf{5}$. Análisis casuístico: Sentencia de la Corte Superior de Justicia de Piura (Exp. $\mathrm{N}^{\circ} 5581$ 2015-23-2001-JR-PE-01), 5.1. Alcances generales de la sentencia, 5.2. Los hechos materia de investigación, 5.3. Los fundamentos jurídicos del voto en mayoría, 5.4. Toma de posición respecto de los argumentos del voto en mayoría de la sentencia: ¿Es correcto el juicio de subsunción realizado? ¿Existe una correcta adecuación típica?

\section{ABSTRACT}

1. Dogmatic analysis of the crime of embezzlement, 1.1. Criminal modalities: embezzlement by appropriation and embezzlement by use, 1.2. The material elements, 2 . The crime of embezzlement as a crime of breach of duty, 3. The typical element of the functional relationship: the functional link by reason of their position, 4 . The functional relationship in fact: does the de facto official maintain the functional relationship with flows and effects ?, 5. Casuistic analysis: Judgment of the Superior Court of Justice of Piura (Exp. N ${ }^{\circ} 5581-$ 2015-23-2001-JR-PE-01), 5.1. General scope of the sentence, 5.2. The facts subject to investigation, 5.3. The legal bases for majority voting, 5.4. Taking a position regarding the arguments of the majority vote of the sentence: Is the subsumption judgment carried out correct? Is there a typical correct fit?

\section{RESUMO}

1. Análise dogmática do crime de peculato, 1.1. Modalidades criminais: peculato por apropriação e peculato por uso, 1.2. Os elementos materiais, 2 . $O$ crime de peculato como crime de violação do dever, 3. O elemento típico da relação funcional: o vínculo funcional em razão do cargo, 4. A relação funcional de fato: o funcionário de fato mantém a relação funcional com fluxos e efeitos?, 5. Análise casuística: Acórdão do Superior Tribunal de Justiça de Piura (Exp. ${ }^{\circ}$ 5581-2015-23-2001-JR-PE-01), 5.1. Âmbito geral da frase, 5.2. Os factos sujeitos a investigação, 5.3. As bases jurídicas da votação por maioria, 5.4. Posicionar-se sobre os argumentos da maioria dos votos da sentença: A sentença de subsunção realizada é correta? Existe um ajuste correto típico? 


\section{Análisis dogmático del delito de peculado}

El delito de peculado -tanto en su modalidad dolosa como culposa- se encuentra tipificado en el artículo $387^{\circ}$ del Código Penal ${ }^{1}$.

Este delito doloso consiste en el injusto penal cometido por el funcionario o servidor público, que en beneficio personal o de terceros, se "apropia" o "utiliza", en cualquier forma, caudales o efectos públicos, cuya administración o custodia le esté conferida por razón del cargo que desempeña. Por lo tanto, el delito de peculado culposo se configura cuando el funcionario o servidor público, por culpa o negligencia, da ocasión, permite, tolera u origina que un tercero sustraiga de la administración pública, caudales o efectos que están confiados por razón del cargo que desempeña en esta $^{2}$.

\subsection{Modalidades delictivas: peculado por apropiación y peculado por utilización}

El tipo penal de peculado (art, $387^{\circ}$ del C.P,) -a diferencia de la forma como se prescribe en el derecho penal comparado, que emplean los verbos de sustraer, procurar y hurtar-, contiene como verbos rectores del injusto penal el acto de apropiar $y$ utilizar. Estos verbos rectores permiten comprender que existen dos formas de

\footnotetext{
${ }^{1}$ El antecedente legal de este delito se encuentra en el artículo $346^{\circ}$ del Código Penal de 1924. La redacción del actual tipo penal es, en su mayoría, una reproducción in extenso de este artículo. $Y$ los cambios son superficiales como, por ejemplo: (1) el uso del tiempo de los verbos "apropiarse" y "utilizar", y (2) el monto de la pena a imponer. Estos cambios al tipo penal fueron en aras de una correcta regulación de este injusto penal, con la finalidad de eliminar algún vacío legal que pudiera dar lugar a la impunidad: Cfr. Abanto Vásquez, Manuel (2007). Los delitos contra la administración pública en el Código penal peruano. Lima: Palestra, p. 336; Rojas Vargas, Fidel (2007). Delitos contra la administración pública, 4 Edición. Lima: Grijley, p. 478.

2 Vide: Abanto Vásquez, Manual A. (2003). Los delitos contra la administración pública en el Código penal peruano. Lima: Palestra, p. 330; Rojas Vargas, Fidel (2007). Delitos contra la administración pública, 4a edición. Lima: Grijley, p. 478; Salinas Siccha, Ramiro (2009). Delitos contra la administración pública, $5^{a}$ edición. Lima: Grijley, p. 403; Montoya Vivanco, Yvan (2015). Manual sobre delitos contra la administración pública. Lima: PUCP IDEHPUCP, p. 106; Frisancho Aparicio, Manuel (2011). Delitos contra la administración pública, 4a edición. Lima: Editora Fecat, p. 325; Hugo Álvarez, Jorge B. y Huarcaya Ramos, Betty S. (2018). Delitos contra la administración pública. análisis dogmático, tratamiento jurisprudencial y acuerdos plenarios. Lima: Gaceta Jurídica S.A., p. 204; Hugo Vizcardo, Silfredo Jorge (2016). El delito de peculado. En: Gaceta Penal \& Procesal penal. Delitos contra la administración pública cometidos por funcionarios públicos, $1^{\text {a }}$ edición. Lima: Gaceta Jurídica, p. 245; Salinas Sichha, Ramiro (2016). El delito de peculado en la legislación, jurisprudencia y doctrina peruana. En: Gaceta Penal \& Procesal penal. Delitos contra la administración pública cometidos por funcionarios públicos, $1^{a}$ edición. Lima: Gaceta Jurídica, p. 275; Benavente Chorres, Hesbert y Calderón Valverde, Leonardo (2012). Delitos de corrupción de funcionarios. Lima: Gaceta Penal \& Procesal Penal, p. 164.
} 
materializarse el hecho delictivo: peculado por apropiación y peculado por utilización $n^{3}$.

La diferencia entre estas dos modalidades delictivas consiste básicamente en la devolución de dichos caudales o efectos ${ }^{4}$. Por su parte, la Corte Suprema se ha manifestado al respecto, en la misma línea.

El primer caso [apropiación] estriba en hacer suyo caudales o efectos que pertenecen al Estado, apartándolo de la esfera de la función (sic.) de la administración pública y colocándose en situación de disponer de los mismos. En el segundo caso [utilización], utilizar, se refiere al aprovecharse de las bondades que permite el bien (caudal o efecto) sin tener el propósito de apoderarse para sí o para un tercero ${ }^{5}$.

La modalidad típica del peculado por apropiación consiste en que el sujeto activo del delito posee, ya consigo, los caudales o efectos del cual entra en disposición personal contraviniendo sus deberes funcionales ${ }^{6}$.

Este supuesto delictivo estriba en hacer suyo o para tercero los caudales o efectos que pertenecen al Estado, apartándolo de la esfera de la función de la administración pública y colocándose en situación de disponer de los mismos. Esta postura ha sido adoptada por la jurisprudencia de la Corte Suprema.

\footnotetext{
${ }^{3}$ En la doctrina penal peruana minoritaria cuestiona estas dos modalidades delictivas. Sostiene la incompatibilidad de ambos criterios para ser regulados bajo un mismo tipo penal. Estas conductas tienen un efecto excluyente: en el delito de peculado por apropiación, el sujeto activo, tendría una mayor ventaja en la atenuación de la pena, la cual se vería reflejada cuando devuelve los caudales o efectos de las que en primera instancia se había apropiado, contrario sensu, en el peculado por utilización, habría una desventaja que no podría ser percibida: Hugo Álvarez, Jorge (2002). Delitos cometidos por funcionarios públicos contra la administración pública. Lima: Gaceta, p. 106

${ }^{4}$ Cfr. Abanto Vásquez, Manuel (2003). Los delitos contra la administración pública en el Código Penal peruano. Lima: Palestra editores, p. 296. El Acuerdo Plenario № 4-2005, fundamento 7, hace una distinción entre estas dos modalidades delictivas: "la apropiación o utilización. En el primer caso estriba en hacer suyos caudales o efectos que pertenecen al Estado, apartándolo de la esfera de la función de la Administración Pública y colocándose en situación de disponer de los mismos. En el segundo caso: utilizar, se refiere al aprovecharse de las bondades que permite el bien (caudal o efecto), sin tener el propósito final de apoderarse para sí o para un tercero".

${ }^{5}$ Ejecutoria Suprema emitida el 9 de febrero de 2010, R. N. 5230-2008. En: Compendio jurisprudencia sistematizada. Prevención de la corrupción y justicia penal. Instituto de Democracia y derechos humanos de la Pontificia Universidad Católica del Perú IDEHPUCP, 2014.

${ }^{6}$ Rojas Vargas, Fidel. Óp., cit., p. 490.
} 
En el delito de peculado doloso, el punto de partida para establecer la relevancia o irrelevancia penal de la conducta imputada a los recurrentes, además de la posición en la esfera institucional, está en acreditar si hubo, un desplazamiento o desmedro patrimonial de los caudales o efectos de la esfera de dominio personal del Estado, a la esfera de dominio personal del funcionario público o de un tercero, debiendo la prueba orientarse a determinar si existe un desbalance respecto de los bienes que en su momento le fueron conferidos con motivo de su gestión ${ }^{7}$.

En esta modalidad delictiva, el sujeto simplemente no administra los bienes destinándolos a la función pública para la que estaban destinados, sino dispone de ellos como si formaran parte de su propio patrimonio. En efecto, la conducta del funcionario peculador debe entenderse como una apropiación sui generis, puesto que él no sustrae los bienes, sino, ellos ya estaban en su poder de disposición en función de su cargo ${ }^{8}$.

En consecuencia, esta modalidad típica de apropiación se configura cuando el agente se apodera, adueña, atribuye, queda, apropia o hace suyo los caudales o efectos del Estado que le han sido confiados en razón de su cargo al interior de la administración pública para que aquel -funcionario o servidor público- pueda percibirlos, custodiarlos ${ }^{9}$.

Por el contrario, si no existe apropiación la conducta es atípica según la jurisprudencia nacional. Así mismo, es de señalar que la devolución de lo apropiado no tiene

\footnotetext{
7 Ejecutoria Suprema del 5 de abril de 2010, R. N No 62-2009-Ica. VOCAL PONENTE: Rodríguez Tineo, Duberlí. En: Rojas Vargas, Fidel (2012). Código penal. Dos décadas de jurisprudencia, Tomo I. Lima: Ara Editores, p. 235.

${ }^{8}$ Abanto Vásquez, Manuel. Óp., cit., pp. 342.

${ }^{9}$ La jurisprudencia peruana refrenda esta tesis: Ejecutoria Suprema del 05 de julio de 2002, Exp. No 3520-2001, Cajamarca "De autos aparece que al encausado se le imputa la comisión del delito de peculado toda vez que en su condición de Teniente Alcalde y Presidente de la Comisión de Economía y encargado del puesto regulador de la venta de arroz giro un cheque en calidad de préstamo para comprar calaminas para el techo de su casa, monto que nunca devolvió; se apropió de una suma de dinero al no haber depositado en el Banco de la Nación y se apropió de sacos vacíos de arroz"; Ejecutoria Suprema del 11 de mayo 2004, R. N. № 40-2003, Apurímac "El delito de Peculado, que consiste en la apropiación de bienes o caudales que hayan sido confiados en razón de su cargo, más no en lo establecido por el artículo $185^{\circ}$ del Código Penal, esto es, en lo referente a que los justiciables por su condición de funcionarios públicos, el hecho de apropiarse y sustraer efectos del Estado, que le han sido dados en custodia por el cargo que desempeñaban, no constituye hurto en modo alguno, sino como ya se ha dicho constituye el delito de peculado".
} 
efectos penales, pues ya el delito se encuentra consumado. A lo más se puede tomar en cuenta a efectos de determinar la pena.

La modalidad típica del peculado por utilización consiste en el acto de usar, emplear, aprovechar, disfrutar y beneficiarse de las bondades que permite los caudales o efectos estatales, sin tener el propósito final de apoderarse para sí o para un tercero $^{10}$. El agente, en esta modalidad delictiva, no tiene el animus o propósito de adueñarse, sino simplemente de servirse del bien público en su propio beneficio.

En este caso, el funcionario o servidor público no busca actuar como propietario, su finalidad es exclusivamente de aprovecharse, mediante el uso, de los caudales o efectos.

En esta modalidad, el tipo penal no exige el desplazamiento de los caudales o efectos de la esfera física del dominio de la administración a la esfera privada. La consumación se genera en un contexto interno de control del funcionario público ${ }^{11}$, por lo que se exige un control normativo.

\subsection{Los elementos materiales}

El Acuerdo Plenario $\mathrm{N}^{\circ} 4-2005^{12}$, ha precisado los elementos típicos del delito de peculado, los cuales deben concurrir en el ilícito penal para su configuración del injusto penal. Los elementos materiales del tipo penal son: relación funcional, percepción, administración, custodia, apropiación o utilización, caudales y efectos.

La relación funcional comprende al vínculo funcional entre el sujeto activo y los caudales y efecto. Esta relación funcional comprende el poder de vigilancia y control sobre el objeto material del delito como componente típico. Esto es la competencia del cargo, la confianza en el funcionario en virtud del cargo, el poder de vigilar y cuidar los caudales o efectos ${ }^{13}$.

${ }^{10}$ Cfr. Rojas Vargas, Fidel. Óp., cit., p. 491; Salinas Siccha, Ramiro. Óp., cit., p. 312.

${ }^{11}$ Rojas Vargas, p. 490.

12 Pleno Jurisdiccional de las Salas penales Permanente y Transitoria de la Corte Suprema de Justicia, Acuerdo Plenario $\mathrm{N}^{\circ}$ 4-2005/CJ-116. Asunto: Definición y estructura típica del delito de peculado. Art, $387^{\circ}$ C.P., fundamento jurídico 6.

${ }^{13}$ Cfr. Acuerdo Plenario No 4-2005/CJ-116, fundamento jurídico 6. 
La percepción comprende el acto de captar o recepcionar caudales y efectos, siempre

lícitos. Y la custodia consiste en la posesión, conservación y vigilancia debida por el funcionario o servidor público de los causales y efectos ${ }^{14}$.

La apropiación consiste hacer suyo los caudales o efectos de la administración pública.

Y la utilización comprende el acto de aprovecharse de los beneficios de los causales o efectos, sin el propósito final de apoderarse para sí o para un tercero ${ }^{15}$.

Los caudales son bienes en general de contenido económico, incluido el dinero. Y los efectos son todos aquellos objetos, cosas o bienes que representan un valor patrimonial, incluyendo los títulos valores negociables ${ }^{16}$.

\section{EI delito de peculado como delito de infracción de deber}

Los delitos de infracción de deber ${ }^{17}$ se desarrollan en el injusto penal y es la vulneración de la obligación, entendida como deber especial, surgido fuera de la norma penal que origina tal calificación, como punto central de referencia típica, con calidad de autor. Es así que toda persona que posee un deber especial tiene el deber de garantizar el principio de la no lesividad de los intereses patrimoniales de la administración pública.

La actual doctrina jurídico-penal -nacional ${ }^{18}$ e internacional-, más allá de las críticas ${ }^{19}$, mantiene la postura que los delitos contra la administración pública son delitos de

${ }^{14}$ Cfr. Acuerdo Plenario $\mathrm{N}^{\circ} 4-2005 / \mathrm{CJ}-116$, fundamento jurídico 6.

${ }^{15}$ Cfr. Acuerdo Plenario $\mathrm{N}^{\circ} 4-2005 / \mathrm{CJ}-116$, fundamento jurídico 6.

${ }^{16}$ Cfr. Acuerdo Plenario No 4-2005/CJ-116, fundamento jurídico 6.

${ }^{17}$ Suarez González, Carlos (2001). Los delitos consistentes en la infracción de un deber. Particular referencia a los delitos cometidos por funcionarios. En: Silva Sánchez/Suarez González. La dogmática penal frente a la criminalidad en la administración pública y otros problemas actuales del Derecho penal. Lima: Grijley, p. 151.

18 Vide: Salinas Sichha, Ramiro (2014). Delitos contra la administración pública, $3^{\circ}$ Edición. Lima: Grijley, p. 15, este autor señala que "en los delitos especiales como lo constituye la mayor parte de los delitos contra la administración pública, se tiene como criterio los delitos contra la administración pública, se tiene como criterio para la determinación o delimitación de la autoría y participación, la teoría de los delitos de infracción de deber formulada desde la óptica de Claus Roxin".

19 Vide: Schünemann, Bernd (2006). El dominio sobre el fundamento del resultado: Base lógicoobjetiva común para todas las formas de autoría incluyendo el actuar en lugar de otro. En: Revista de Derecho Penal, Donna, Alberto E. (Director) pp. 37-40: el autor señala que, el hecho de que Roxin haya propagado la categoría de los delitos de infracción de deber, en contrapartida con los delitos de dominio, se explica -en su opinión del autor-, por la circunstancia de que partía del estado de las nociones generales de aquel. Entonces, tanto en sentido jurídico-teórico, como también en relación con la dogmática de los delitos de omisión (...). En consecuencia, -continúa el autor que-, los delitos de infracción de un deber especial extrapenal producen consecuencias 
infracción de deber ${ }^{20}$, criterio donde no es el dominio del hecho presupuesto fundamental para imputar autoría, sino que ésta requiere de la vulneración de un deber especial extrapenal, debiendo ser cada elemento normativo, interpretado sobre la base del correcto desempeño del funcionario en el campo de acción de sus funciones.

Los delitos cometidos por funcionarios públicos a diferencia de los delitos comunes, guardan una estrecha relación de protección de las actividades públicas para el cual fueron confiados. Pero esto no deriva en una imputación penal del agente con capacidad especial, por tener, por ejemplo, calidad de funcionario público, como característica abstracta, sino que esto se circunscribe como una particularidad que determina su relación especial (como por ejemplo en el delito de peculado), debiendo además actuar en ejercicio competente de dicha función pública.

En la doctrina penal se discute mucho acerca de la naturaleza jurídica del delito de peculado. No obstante, para la mayoría, la postura sostiene que el peculado es un delito de infracción al deber. Esta tesis ha sido refrendada por la Corte Suprema de la Republica, en sendas jurisprudencias ${ }^{21}$, señalando que:

jurídicas, obviamente, primero sólo en el ámbito jurídico especial fuera del Derecho Penal, mientras que para la equiparación de la omisión con el hacer activo en el ámbito penal se necesitan, naturalmente criterios penales específicos (...).

${ }^{20}$ La infracción de deber, si bien, de forma similar que los delitos de dominio, y también los delitos especiales, se desarrollan en el injusto penal, en estos casos, es la vulneración de la obligación, entendida como deber especial, surgida fuera de la norma penal, que origina tal calificación, como punto central de referencia típica, con la calidad de autor: Suarez González, Carlos (2001). Los delitos consistentes en la infracción de un deber. Particular referencia a los delitos cometidos por funcionarios. En: Silva Sánchez, Jesús M. y Suarez González, Carlos (Coordinadores). La dogmática penal frente a la criminalidad en la administración pública y otros problemas actuales del derecho penal. Lima: Grijley, p. 151.

${ }^{21}$ Sentencia de la Sala Penal Permanente de la Corte Suprema de Justicia de la República, 16 de agosto de 2017, R. N. N 615-2015-Lima, Fundamento 2.1.1: En doctrina se ha establecido que el delito de peculado constituye un delito especial de infracción de deber fundamento en instituciones positivas. Es delito especial porque típicamente restringe los contornos de la autoría a determinados sujetos cualificados -en este caso, de funcionarios y servidores públicos-, pero, al mismo tiempo, se trata de un delito de infracción de deber porque el fundamento de la responsabilidad penal a título de autor reside en el quebrantamiento de un deber positivo asegurado institucionalmente (Caso: Diarios Chicha). Esta misma postura se ha tomado en cuenta en las siguientes jurisprudencias: Sentencia de la Sala Penal Permanente de la Corte Suprema de Justicia de la República, 23 de noviembre de 2016, R. N. N 1780-2015-Tacna, considerando tercero; Sentencia de la Sala Penal Permanente de la Corte Suprema de Justicia de la República, 26 de julio de 2018, R. Casación N 1004-2017-Moquegua, fundamento segundo; Sentencia de la Segunda Sala Penal Transitoria de la Corte Suprema de Justicia de la República, 11 de julio de 2017, Casación No 102-2016-Lima, fundamento décimo quinto; Sentencia de la Sala Penal Permanente de la Corte Suprema de Justicia de la República, 26 de setiembre de 2018, R. N. N 1940-2017-Áncash; Sentencia de la Primera Sala Penal Transitoria de la Corte Suprema de 
El delito de peculado es uno de infracción de deber (más específicamente, un delito especial de deber). Se construye sobre la base de deberes que se imponen a determinadas personas que, por su vinculación institucional con ciertos bienes jurídicas, tienen una obligación específica de mantener una situación social determinada. Lo que se castiga es, en buena cuenta, la infracción de normas muy específicas - para la constitución del tipo penal es necesaria la presencia de un deber especial- $^{22}$. (lo resaltado en negrita es nuestro)

Cuarto. Es un delito de infracción de deber, por lo que, quien vulnera este compromiso con el Estado siempre será autor, independientemente de la importancia de su contribución o dominio del hecho [SÁNCHEZ-VERA GÓMEZ-TRELLES, Javier. Delito de infracción de deber y participación delictiva. Marcial Pons, Barcelona, 2002, p. 183]. De ahí la importancia de establecer quién es el autor típico, que debe ser funcionario o servidor público y tener los bienes del Estado confiados en razón de su cargo ${ }^{23}$.

En consecuencia, la imputación penal en el delito de peculado se sustenta en la infracción de un deber jurídico asignado por razón de su cargo. Es decir, los elementos típicos surgen de la infracción de un deber normativo especial del agente, independientemente de la forma de ejecutar dicha infracción ${ }^{24}$.

Justicia de la República, 4 de octubre de 2017, R. N. No 2921-2016-Huancavelica; Sentencia de la Primera Sala Penal Transitoria de la Corte Suprema de Justicia de la República, 13 de setiembre de 2017, R. N. N 1362-2016-Puno; Sentencia de la Sala Penal Permanente de la Corte Suprema de Justicia de la República, 6 de febrero de 2014, R. N. N 2413-2012-Piura; Sentencia de la Sala Penal Permanente de la Corte Suprema de Justicia de la República, 13 de setiembre de 2016, Casación N 506-2013-Puno; Sentencia de la Sala Penal Permanente de la Corte Suprema de Justicia de la República, 6 de julio de 2016, R. N. No 1211-2016Apurímac; Sentencia de la Sala Penal Permanente de la Corte Suprema de Justicia de la República, 12 de diciembre de 2014, R. N. N 765-2014-Pasco; Sentencia de la Sala Penal Permanente de la Corte Suprema de Justicia de la República, 23 de abril de 2018, R. N. No 2390-2017-Áncash.

${ }^{22}$ Sentencia de la Sala Penal Permanente de la Corte Suprema de Justicia de la República, 15 de mayo de 2019, R. Casación $\mathbf{N}^{\circ}$ 1500-2017-Huancavelica, fundamento primero. Ponente: Cesar San Martín Castro.

${ }^{23}$ Sentencia de la Sala Penal Permanente de la Corte Suprema de Justicia de la República, 7 de octubre de 2015, Casación N 160-2014-Áncash. Voto de los señores Jueces Supremos Neyra Flores y Loli Bonilla, fundamento cuarto.

${ }^{24}$ Un sector minoritario se empeña en señalar que el delito de peculado es un delito de dominio del hecho. Por cuanto afirman que la imputación jurídico penal se fundamenta en el dominio del hecho que tiene el sujeto. Sin embargo, esta postura es minoritaria, de ahí el consenso en la doctrina cuando se señala que el delito de peculado es una figura delictiva que restringe su radio de imputación jurídico-penal a determinados sujetos, los cuales necesariamente tienen que reunir la calidad de funcionarios o servidores públicos a fin de que puedan responder como autores. 
En similar sentido, la jurisprudencia de la Corte Suprema, recaído en el R. N. No $615-$ 2015-Lima, ha señalado que:

En doctrina se ha establecido que el delito de peculado constituye un delito especial de infracción de deber fundamentado en instituciones positivas [Vid. Reaño Peschiera, José Leandro. La administración de caudales por delegación de competencias. En Revista Peruana de Doctrina y Jurisprudencia Penales, $N^{\circ}$ 4, Lima, Grijley, 2003, p. 351]. Es delito especial porque típicamente restringe los contornos de la autoría a determinados sujetos cualificados -en este caso, de funcionarios y servidores públicos-, pero, al mismo tiempo, se trata de un delito de infracción de deber porque el fundamento de la responsabilidad penal a título de autor reside en el quebrantamiento de un deber positivo asegurado institucionalmente [Ibídem $]^{25}$. (lo resaltado en negrita es nuestro)

En consecuencia, el delito de peculado, por su particularidad, constituye un delito especial $^{26}$ de infracción de deber ${ }^{27}$, vinculado a instituciones positivizados porque el fundamento de la responsabilidad penal reside en el quebrantamiento de un deber asegurado institucionalmente. Por tanto, quien no tenga la cualidad de funcionario

SALAZAR SÁNCHEZ, Nelson. En: Actualidad Jurídica. Tomo 135. Gaceta Jurídica. Lima. 2005. p 81.

${ }^{25}$ Sentencia de la Sala Penal Permanente de la Corte Suprema de Justicia de la República, 16 de agosto de 2016, R. N. N 615-2015-Lima, fundamento 2.1.1.; en similar sentido la Ejecutoria Suprema del 11 de octubre de 2004, R. N. N 027-04- Sullana, ha señalado que "el tipo penal previsto en el artículo $387^{\circ}$ del Código penal, es un delito especial, que exige como elemento constitutivo para su configuración una determinada cualidad del agente, lo que conlleva a establecer que la esfera de los autores está limitada a determinados sujetos" en: Urquizo Olaechea, José (2010). Código Penal comentado, T. I. Lima: Idemsa, pp. 1054-1055.

${ }^{26}$ La consideración de un tipo penal como delito especial atiende exclusivamente a su estructura formal, mientras que la clasificación de deber despliega sus efectos a nivel de las estructuras materiales de imputación: Reaño Peschiera, Leandro (2009). Formas de intervención en los delitos de peculado y tráfico de influencias. Lima: Jurista Editores, pp. 22-23. En similar sentido, la Ejecutoria Suprema del 4 de junio de 1999, Exp. № 5210-98-Lima: "El delito de peculado constituye un delito especial que exige una calificación especial al sujeto activo, que es la de ser funcionario o servidor público, siendo esta exigencia un aspecto del tipo objetivo, que necesariamente debe verificarse en el caso concreto para establecer dicha conducta como típica". ${ }^{27}$ Reaño Peschiera, Leandro (2009). Formas de intervención en los delitos de peculado y tráfico de influencias. Lima: Jurista Editores, p. 25. En la misma línea, la Ejecutoria Suprema del 5 de abril de 2010, R. N. No 62-2009-Ica: El delito de peculado doloso es un delito de infracción de deber integrado por un deber positivo o deber institucional especifico que delimita el ámbito de competencia del actuante, circunscribiéndolo al rol especial de funcionario o servidor público, quedando obligado así a ejercerlo correctamente, de tal manera que cuando defraude las expectativas normativas referidas a su rol especial incurre en una responsabilidad penal de corte institucional". 
o servidor público no podrá ser considerado autor de un delito especial como el delito de peculado ${ }^{28}$.

\section{El elemento típico de la relación funcional: el vínculo funcional por razón de} su cargo

En el delito de peculado es condición sine qua non que el bien público, objeto de la apropiación o utilización, esté en posesión del agente en virtud de los deberes o atribuciones del cargo que desempeña dentro de la administración estatal. Es decir, en este delito, los objetos materiales del delito (caudales y efectos) deben estar confiado al funcionario o servidor público por razón de su cargo.

La posesión de los caudales o efectos, de la cual goza el funcionario o servidor público, debe estar confiado, o, en posesión inmediata o mediata de aquellos, en razón del ámbito de la competencia del cargo ${ }^{29}$, determinado o establecido en la ley o normas jurídicas de menor jerarquía como reglamentos, directivas de las instituciones públicas, entre otros ${ }^{30}$. Dicha posesión puede ser inmediata o mediata, es decir, estar en contacto con los caudales y efectos, o darla por asumida, bastando solamente la facultad de disposición jurídica o disposición funcional ${ }^{31}$.

En este sentido, el sujeto activo no solo debe tener la cualidad especial que exige la norma, sino que debe administrar, de manera directa o indirecta, los bienes estatales. Tal posesión implica "funciones activas de manejo y conducción"32, que la doctrina denomina vinculación funcional, lo que comprende tanto relaciones directas con el caudal o efecto como relaciones mediatas, pues sin necesidad de entrar en contacto

28 Gómez Méndez, Alfonso y Gómez Pavajeau, Carlos (2008). Delitos contra la administración pública, $3^{a}$ edición. Colombia, Universidad de Externado de Colombia, p. 128. La jurisprudencia peruana, 11 de octubre 2004, R. N. № 027-04, Sullana-Piura sostiene la misma línea: El tipo penal previsto en el artículo 387 del Código penal, es un delito especial que exige como elemento constitutivo para su configuración una determinada cualidad del agente, lo que conlleva a establecer que la esfera de los autores están limitada a determinados sujetos, siendo el bien jurídico tutelado en este tipo penal lesionado por la conducta de los funcionarios o servidores públicos desde dentro, es decir por los intraneus. Consecuentemente, el particular al carecer de un supuesto de hecho fundamental para la estructuración típica de la conducta, gozar de la calidad de funcionario o servidor público, no puede ser autor material del delito de peculado.

${ }^{29}$ Salinas Siccha, Ramiro (2014). Delitos contra la administración pública. Lima: Editora Jurídica Grijley, p. 320

${ }^{30}$ Salinas Siccha, Ramiro (2014). Ob., cit., p. 321.

${ }^{31}$ Vide: Bernal Pinzón, Jesús (1965) Delitos contra la administración pública y asociaciones para delinquir. Bogotá: Editorial Themis, p. 23.

${ }^{32}$ Rojas Vargas, Fidel (2017). Delitos contra la administración pública, 4a edición. Lima: Grijley, p. 490. 
físico con los bienes el funcionario puede disponer de ellos, en razón de ser el responsable de la unidad administrativa.

Este elemento material de la "relación funcional" permite sostener que el injusto penal de peculado trasciende el ámbito meramente patrimonial, para constituirse dentro de los delitos que infringe los deberes de garantía y confianza específicos asumidos por el funcionario o servidor público en virtud de la función ejercida en la entidad pública.

Es importante tener en cuenta que la relación funcional sirve para restringir o limitar el círculo de autores, circunscribiéndolo solo a aquellos que posean los caudales o efectos públicos por razón del cargo que desempeñan, excluyendo la hipótesis de autoría a los que no gozan o no tienen tal relación. En este sentido, la vinculación funcional que posee el sujeto activo del delito de peculado con el patrimonio es el elemento normativo nuclear que vincula la conducta del funcionario público con el sentido de relevancia penal de la tipicidad del delito de peculado.

Esta vinculación funcional cumple dos funciones: primero, sirve para limitar el círculo de autores, circunscribiendo solo a aquellos que tienen los caudales o efectos públicos por razón del cargo que realizan, excluyendo los casos de autoría a los que no gozan de tal relación funcional; y, segundo, constituye un límite que debe ser advertido por los operadores de justicia, de lo contrario se lesionaría el principio de legalidad que sustenta la aplicación de las normas penales ${ }^{33}$.

Y por su parte, Rojas $\operatorname{Varas}^{34}$, señala que en esa relación funcional o vinculo funcional: (i) El funcionario tiene el control directo de los caudales o efectos (es el detentador material de los bienes, como el jefe de logística, el administrador que tiene la caja chica o el funcionario que está en contacto con el bien a efectos de brindar servicios). Ahí existe un control directo, una posesión directa del bien. (ii) El titular o funcionario de nivel no está en relación directa con los bienes ni los posee físicamente, o simplemente éstos no están en un determinado territorio que él administra. Sin embargo, posee una disposición jurídica de los bienes, entre ellos,

${ }^{33}$ Alcocer Povis, Eduardo (2005). La autoría y participación en el delito de peculado. Comentarios a partir del caso Montesinos-Bedoya. En Actualidad Jurídica, Tomo 42, Lima, 2005.

34 Rojas Vargas, Fidel (2016). Manual operativo de los delitos contra la administración pública cometidos por funcionarios públicos. Lima: Editorial Nomos \& Thesis E.I.R.L., pp. 251-252 
el titular del pliego, el administrador, el feje de logística que no necesariamente tiene a los bienes en un área específica, sino que desde su gerencia dispone que los bienes sean entregados a terceros o él mismo se los lleva. Es decir, utilizan su "poder de decisión".

En consecuencia, es importante resaltar que el tipo penal de peculado hace referencia expresa a un funcionario público no in abstracta, sino contextualizado a un segmento concreto de la función pública "por razón de su cargo". Es decir, para que se configure el comportamiento típico por apropiación o utilización, los bienes públicos, sea este caudales o efecto, objeto material del delito, deben encontrarse en posesión, ya sea mediata o inmediata, del sujeto activo y ellos en virtud a los deberes o atribuciones del cargo que ostenta al interior de la administración estatal. Por lo que, si dicha relación funcionaria de estricta base jurídica entre el sujeto activo y bien público que posee no existe, no podrá hablarse del delito de peculado.

En este sentido, prima facie debemos mencionar que no todo funcionario público -por su sola condición- podrá ser sujeto activo del delito de peculado, porque si en un hecho concreto, este elemento de la "relación funcional" no se corrobora, el hecho no se puede subsumir en el tipo penal de peculado, por más que exista apropiación de los causales o efectos del Estado ${ }^{35}$.

4. La relación funcional de hecho: ¿el funcionario de facto mantiene la relación funcional con los caudales y efectos?

Para los "funcionarios de facto", al contar con la anuencia, orden o disposición de los directos responsables o competentes de la administración o custodia del patrimonio estatal, su accionar es público, exclusivo, pacífico, continuo y lícito dentro del marco de la administración pública. Y cualquier persona toma conocimiento de que tal funcionario o servidor es el encargado de administrar, percibir o custodiar los bienes del Estado. En este sentido, es factible considerar como autor del delito de

35 Clínica Jurídica de Acciones de Interés Público de la Universidad Nacional de la Amazonía Peruana (2021). Informe jurídico con la finalidad de ponerlo a su disposición, considerando los problemas que plantea el Expediente $\mathrm{N}^{\circ}$ 51-2013-0-1905-JR-PE-01. Informe elaborado con el apoyo del Instituto de Democracia y Derechos Humanos de la Pontificia Universidad Católica del Perú - IDEHPUCP. 
peculado a los funcionarios de facto, siempre y cuando las leyes o reglamentos internos no prohíban de manera expresa aquellas delegaciones o encargos ${ }^{36}$.

En ese sentido, las simples delegaciones de funciones o los encargos temporales o coyunturales de los bienes del Estado a funcionarios o servidores públicos de modo alguno genera el elemento material de la relación funcional o vinculo funcional que exige el tipo penal de peculado.

5. Análisis casuístico: Sentencia de la Corte Superior de Justicia de Piura (Exp. $N^{\circ}$ 5581-2015-23-2001-JR-PE-01)

\subsection{Alcances generales de la sentencia}

El análisis casuístico comprende a la Sentencia del Juzgado Penal Colegiado Especializado en Delitos de Corrupción de Funcionarios de la Corte Superior de Justicia de Piura del 10 de setiembre de 2021, recaído en el Exp. № 5581-2015-232001-JR-PE-01, Resolución N $32^{37}$.

El juicio de subsunción para la correcta tipificación de los hechos ha generado discrepancia entre los magistrados. En este sentido, el voto en mayoría ha resuelto condenar a los acusados por el delito de peculado doloso, segundo párrafo del art. 387 C.P.; bajo el título de imputación de autor al alcalde de la Municipalidad Provincial de Morropón (en adelante MPM) y cómplice primario al asesor legal. En consecuencia, le imponen ocho años de pena privativa de libertad e inhabilitación por ocho. Y fijan la suma de S/ 550, 000.00 (quinientos cincuenta mil con 00/100 soles) por concepto de reparación civil, que deberá ser cancelado por los sentenciados de manera solidaria a favor del Estado.

El voto singular resuelve absolver a los acusados (alcalde de MPM y asesor legal) de los cargos imputados por el Ministerio Público. En consecuencia, dispone anular los antecedentes que se hubiera generado como secuela de la presente causa.

\subsection{Los hecho materia de investigación}

\footnotetext{
${ }^{36}$ En este mismo sentido, Abanto Vásquez, Manuel [Los delitos contra la administración pública en el Código Penal peruano, $2^{\text {a }}$ Edición, Lima: Palestra Editores, p. 360] señala que "el funcionario de facto ejerce funciones en forma ilícita, pero sin cumplir en realidad con los requisitos legales o sin haber cumplido con las formalidades de ley".

${ }^{37}$ Ver la sentencia: Exp. 05581-2015-22-2001-JR-PE-H1.pdf
} 
Los hechos materia de investigación son:

1. En el año 2007, 18 trabajadores de la MPM, solicitaron el otorgamiento de un incremento remunerativo ascendente a S/. 100.00 (cien soles), el cual fue aprobado mediante Resolución de Alcaldía N 946-2006-MPMCH-A de 18 de setiembre de 2006, para el personal estable. Este pedido fue desestimado mediante sendas resoluciones de alcaldía, señalando que los peticionantes no se encontraban inmersos dentro de los alcances del procedimiento de negociación bilateral regulado por el D.S. $\mathrm{N}^{\circ} 070-85$ PCM que permite los ajustes remunerativos conforme a Ley.

2. El 10 de noviembre de 2011, mediante Expediente $\mathrm{N}^{\circ}$ 12901-2011, 18 servidores de la MPM solicitan el pago de incrementos remunerativos adquiridos vía negociación colectiva, incrementos que se dieron mediante: a) Resolución de Alcaldía $\mathrm{N}^{\circ}$ 1266-2000-MPM-CH-A de 29 de noviembre de 2000, b) Resolución de Alcaldía N 1022-2000-MPM-CH-A de 06 de julio de 2002, c) Resolución de Alcaldía N 2011-2001-MPM-CH-A de 26 de diciembre de 2001, c) Resolución de Alcaldía N 1070-2002-MPMCH-A de 29 de agosto de 2002 y, e) Resolución de Alcaldía N 946-2006MPM-CH-A de 18 de setiembre de 2006.

3. El 29 de diciembre de 2011, el alcalde de la MPM, emitió la Resolución de Alcaldía No 1130-2011-MPM-CH-A, mediante la cual resuelve reconocer los incrementos remunerativos derivados de pactos colectivos $\mathrm{y}$ dejados de percibir a 18 trabajadores municipales. Mediante la cual dispone que la unidad de recurso humanos a través del área de remuneraciones practique la liquidación de reintegros remunerativos derivados de pactos colectivos dentro del régimen laboral del D. Leg. $\mathrm{N}^{\circ}$ 276.

4. El 21 de setiembre de 2012, la jefa de Recursos Humanos, mediante Informe $\mathrm{N}^{\circ}$ 2221-2012-PMP-CH-A, da cuenta al Director de Administración, que los numerales 9 y 10 de la Resolución de Alcaldía $\mathrm{N}^{\circ}$ 1130-2011-PMP-CH-A, se encuentra inmersos en nulidad y que la citada resolución era irregular. 
5. Con la finalidad de ejecutar la Resolución de Alcaldía $\mathrm{N}^{\circ}$ 1130-2011MPM-CH-A, el alcalde de la MPM cursó sendos documentos (Memorando No 99-2013-MP-CH-A y el Memorando N 100-2013-MPCH-A, ambos de fecha 20 de setiembre de 2013) a la Unidad de Recursos Humanos para que implemente, a través del Área de Remuneraciones, las acciones tendientes a la cancelación de reintegros al personal, mediante los cuales se les insta a dar cumplimiento estricto a la acotada resolución de alcaldía, caso contrario se disponía las acciones que resulten necesario en aras de preservar el principio de autoridad, así, en el considerando final de los citados documentos se señala que de acuerdo al artículo 28 del D. Leg. 276, se prevé como falta de carácter disciplinaria la reiterada resistencia al cumplimiento de las órdenes superiores relacionadas con sus labores, que, según su gravedad, pueden ser sancionadas con cese temporal o con destitución, previo proceso administrativo, es decir, se hace acotación que de no dar cumplimiento las indicadas trabajadoras podrían estar sujetas a sanciones.

6. El 31 de enero de 2013, mediante Memorándum N²0-2013-OAF/MPM$\mathrm{CH}$, se dispuso contratar un consultor externo que llevara a cabo lo dispuesto en el artículo segundo de la Resolución de Alcaldía $N^{\circ} 1130$ 2011.-PMP-CH-A, llegando a determinar que no es posible su ejecución por contravenir al ordenamiento jurídico, que los solicitantes no cuentan con los requisitos establecidos en el D. Leg. $\mathrm{N}^{\circ} 276$ y su Reglamento D.S. $\mathrm{N}^{\circ}$ 005-90-PCM y el D.S. N 070-85-PCM; y, que, a pesar de ello, se viene requiriendo reiteradas veces que la dependencia de Unidad de Recursos Humanos y Áreas de Remuneraciones, ejecuten las liquidaciones que otorgan los incrementos por pacto colectivos desde el año 2001 al 2007 a los 18 contratados favorecidos con la resolución cuestionada.

7. El 16 de junio de 2016, mediante dictamen pericial contable, se determinó que la ejecución en parte de la Resolución de Alcaldía $N^{\circ}$ 1130-2011PMP-CH-A, esto es, el pago acumulado de todos los incrementos remunerativos otorgados mediante negociación bilateral entre el año 2001 al 2006, que se viene efectuando en la planilla de remuneraciones desde el 1 de enero de 2012 al 31 de mayo de 2016, a los 18 servidores municipales, 
ha ocasionado un perjuicio económico ascendente a S/ 530375.00 (quinientos treinta mil trescientos sesenta y cinco soles), monto al que debe agregarse S/ 9000.00 (nueve mil soles), que corresponde al pago de honorarios a los consultores externos contratados para determinar la procedencia o improcedencia de los reintegros de incrementos remunerativos de periodos anteriores, cuya opinión no fue tomado en cuenta por la alcaldía.

\subsection{Los fundamentos jurídicos del voto en mayoría}

Los argumentos jurídicos que esgrimieron los magistrados, en mayoría, para condenar a los procesados por el delito de peculado son:

1. El acusado, en su condición de alcalde de la MPM-CH (2011 al 2018), tenía pleno conocimiento que con anterioridad se había solicitado el pago de reintegro de remuneraciones en base a pactos colectivos, y que estos habían sido denegados tanto a nivel administrativo, como judicial, toda vez que los 18 trabajadores no se hacían merecedores a dicho derecho, pues no contaban con la condición laboral necesaria para poder solicitar estos incrementos remunerativos.

2. El acusado, firmó la Resolución de Alcaldía $\mathrm{N}^{\circ}$ 1130-2011-MPM-CH-A de 29 de diciembre de 2011, referida al otorgamiento de beneficios remunerativos por pacto colectivo para 18 trabajadores, la cual fue proyectada por el asesor legal y visada por el gerente municipal, gerente de administración, jefe de presupuesto y el asesor legal.

3. Tomando como referencia la Casación $N^{\circ}$ 1527-2018-Tacna, el órgano colegiado en mayoría, considera que la actividad probatoria antes indicada, advirtió que el acusado, en su condición de alcalde, pese a que tenía conocimiento que se había solicitado el pago de reintegro de remuneraciones en base a pactos colectivos y que estos habían sido denegados tanto a nivel administrativo como judicial, -porque los 18 trabajadores no se hacían merecedores a dicho derecho, porque no contaban con la condición laboral necesaria para poder solicitar estos incrementos remunerativos-, se emitió la Resolución de Alcaldía $\mathrm{N}^{\circ} 1130$ - 
2011-MPM-CH-A en la cual se reconoce a los 18 trabajadores -ya en condición de nombrados- los incrementos que habían dejado de percibir por concepto de pactos colectivos celebrados entre el sindicato y la MPM$\mathrm{CH}$, y ordena que se les cancele el reintegro de todos los pactos colectivos celebrados a partir del 2001 al 2006.

4. La ilicitud de los pagos, está probada con diversos medios de prueba y con el Informe Legal externo. Las sentencias judiciales refrendando la ilegalidad de las peticiones de los trabajadores

5. El informe legal externo abona el dolo del ex alcalde ya que ratificó la antijuridicidad de la aspiración de los 18 trabajadores, y el informe pericial contable debidamente actuado en sede judicial y sin contrariedad técnica por la parte acusada, resultan ser más que suficientes para probarse este ilícito penal, razonablemente, la naturaleza anti-normativa de la decisión.

6. Con la emisión de la Resolución de alcaldía $\mathrm{N}^{\circ} 1130-2011$, se consuma el delito de peculado, tipificado en el artículo 387 del C.P., no representando ser estos "actos preparatorios", pues con lo ordenado por el acusado, en su condición de alcalde, en dicha resolución de alcaldía, se comprometió el patrimonio del Estado (disponibilidad jurídica), al haber ordenado los incrementos remunerativos, derivados de pactos colectivos (pese a que anteriormente ya se había decretado la negación a dichos requerimientos), en ese sentido las liquidaciones y los pagos se realizaron en cumplimiento a lo ordenado en la Resolución de Alcaldía N 1130-2011.

7. El órgano colegiado por mayoría, considera que la conducta se encuentra consumada, ello verificado a través de la emisión de la Resolución de Alcaldía N 1130-2011- MPM- CH-A, emitida con la finalidad de extraer de la esfera de la administración pública el dinero para ingresarse al dominio privado y disponer de ella, pues finalmente los 18 trabajadores se beneficiaron con la emisión de esta resolución y esto se ve corroborado con las declaraciones de los testigos conforme se ha señalado en párrafos precedentes y con los documentales oralizados: Memorándum $\mathrm{N}^{\circ} 099$ 2013-MPM-CH-A, dirigido por el alcalde a la jefa de la Unidad de Recursos Humanos, mediante el cual solicita que la unidad de Recursos 
Humanos, a través del área de remuneraciones, practique la liquidación de reintegros de incrementos remunerativos reconocida a 18 trabajadores, a partir de su contratación bajo el régimen laboral del D. Leg. $\mathrm{N}^{\circ} 276$; con el Memorándum $N^{\circ}$ 100-2013-M PM-CH-A cursado a la jefa del área de remuneraciones, en el cual indica que su persona insiste en desconocer las disposiciones emitidas respecto a la ejecución de la Resolución de Alcaldía N 1130-2011-MPM-CH-A; asimismo, con el Memorándum $\mathrm{N}^{\circ}$ 105-2012- MPM-CH y N 114-2012- MPM-CH-A, dispuso que su área cumpla con dicha obligación, fijándole el plazo de 24 horas, sin que haya cumplido con hacerlo, por lo que le recuerda que la reiterada resistencia constituye falta administrativa que puede ser sancionada; por lo cual le insta para que en el plazo perentorio de 24 horas proceda a practicar las liquidaciones respectivas, conforme lo dispuesto en el artículo segundo de la acotada resolución, bajo responsabilidad.

5.4. Toma de posición respecto de los argumentos del voto en mayoría de la sentencia: ¿Es correcto el juicio de subsunción realizado? ¿Existe una correcta adecuación típica?

La tipicidad es el resultado de la verificación de si la conducta y lo descrito en el tipo, coinciden. A este proceso de verificación se denomina juicio de tipicidad, que es un proceso de imputación donde el intérprete, tomando como base al bien jurídico protegido, va a establecer si un determinado hecho puede ser atribuido a lo contenido en el tipo penal. Es decir, que, si luego de realizado dicho proceso se determina que el hecho encaja en los caracteres abstractos del tipo, existe adecuación típica, caso contrario, nos llevaría a decir que el hecho es atípico.

En este sentido, el proceso de imputación desarrollado por los magistrados en mayoría es defectuoso porque el juicio de subsunción carece de toda lógica jurídica. Por ende, el juicio de tipicidad -que es un acto valorativo encaminado a determinar una prohibición-, es incorrecto porque no se cumple con la tipicidad, es decir, no se ha podido verificar la coincidencia entre la conducta (los hechos) y lo descrito en el tipo penal del delito de peculado (art. $387^{\circ}$ del C.P.).

Sin embargo, el voto en mayoría, resolvió condenar a los acusados por el delito de peculado doloso, utilizando argumentos ilógicos sin un correcto juicio de 
subsunción. Esto nos permite inferir que el voto en mayoría no realizó una adecuada tipificación de los hechos hacia los caracteres del tipo penal, por tanto, no existe, a nuestro juicio, una adecuación típica por las siguientes razones:

1. El procedimiento seguido por el acusado (alcalde de la MPM) respetó todo el procedimiento administrativo general. Es así que, la Resolución de Alcaldía $\mathrm{N}^{\circ}$ 1130-2011-MPM-CH-A fue firmada por el acusado después de cumplir el proceso administrativo, desde gerencia municipal, gerencia de administración, presupuesto, personal, recursos humanos y la proyección de la resolución por el asesor legal. La firma de dicha resolución se llevó a cabo por la confianza en sus funcionarios. Y después de tomar conocimiento del peritaje, dispuso vía memorándum que la gerencia municipal lo evalúe para evitar perjuicios o daños a terceros, o a la propia institución, recibiendo como respuesta que era imposible tomar alguna acción porque la resolución ya estaba firme y consentida, ante esta negativa y al verse perjudicado por algo que había firmado porque sus asesores legales y técnicos le hicieron ver que era legal, dispuso de manera unilateral que se suspendiera el pago, disposición que quedó sin efecto porque la sala civil ordenó que se siga pagando.

2. Los pagos que realizo la MPM no son ilícitos.

a) No se puede determinar a licitud o ilicitud de los pagos con la sola valoración de las declaraciones de los testigos, sin realizar un análisis minucioso de la normativa extrapenal aplicable.

b) No es posible afirmar la ilicitud de los pagos solo porque con anterioridad se negaban dicho pedido mediante resoluciones de alcaldía. Decir por eso que esas peticiones de pagos y reintegro de pagos son ilegales es desconocer los derechos laborales de los trabajadores a una negociación colectiva.

c) Estos beneficios fueron reconocidos en la vía judicial, porque una trabajadora, de los dieciocho beneficiarios, interpuso una demanda judicial y la sala reconoció dicho pacto laboral.

d) Por otro lado, el Informe $\mathrm{N}^{\circ} 460-2011$, emitido por el jefe de presupuesto y planificación indica que existía cobertura presupuestal para poder asumir 
el pago de incrementos remunerativos de pactos colectivos anteriores, siendo por ello que en el artículo 3 de la cuestionada resolución se precisa que el derecho reconocido a los trabajadores se ejecutara a partir del ejercicio presupuestal del año 2012 hacia adelante.

3. No se ha realizado una correcta tipificación, es decir, el juicio de subsunción del voto en mayoría solo determina una incorrecta adecuación típica de los hechos. Pues los magistrados en mayoría solo se han limitado a realizar una descripción somera del tipo penal de peculado, sin verificar si los hechos coinciden con los caracteres abstractos del tipo penal de peculado. En efecto, el juicio de subsunción realizado, no es una adecuada tipificación.

4. No se ha podido demostrar la existencia de la relación funcional entre los acusados (alcalde y asesor legal) y los caudales o efectos de la MPN. Elemento material indispensable para la concurrencia del delito de peculado:

a) Las funciones del alcalde están enmarcadas en la Ley Orgánica de Municipalidades, en el ROF y el MOF. En este sentido, las remuneraciones y presupuesto son funciones exclusivas del cargo del jefe de presupuestos y no del alcalde de la MPM. Una cosa es que el alcalde tenga una responsabilidad política sobre todos los intereses de la MPM, sin embargo, esta responsabilidad es genérica y para cumplir con sus responsabilidades delega funciones $\mathrm{y}$, por ende, delimita responsabilidades.

b) Esto quiere decir que, si bien el alcalde tiene una responsabilidad política sobre los intereses de la MPM, no lo tiene sobre las remuneraciones y presupuestos de dicha entidad. Función que le compete a otro funcionario. En consecuencia, al delegar dicha responsabilidad también está delegando responsabilidades.

c) En este sentido, no se puede sostener que el alcalde tenía una relación funcional con los caudales de la MPM -en lo que respecta a las remuneraciones y presupuestos de dicha entidad-. En consecuencia, si el acusado no tiene dicho vinculación funcional no se puede configurar el 
delito de peculado y, por ende, no puede ser sujeto activo del delito que se le imputa.

d) Si bien el alcalde firmó la Resolución de Alcaldía Nº 11 30-2011-MPMCH-A (29 de diciembre de 2011), para otorgar beneficios remunerativos a dieciocho trabajadores por pacto colectivo, fue proyectada por el asesor legal y visada por el gerente municipal, gerente de administración, jefe de presupuesto y el asesor legal. Esta decisión no fue acatada inmediatamente porque se tenía que recibir el informe del jefe de la oficina de presupuesto, quien también era beneficiario de esa resolución, no apreciando entonces que esa situación supusiera alguna incompatibilidad.

5. Los trámites administrativos realizados por el acusado (alcalde y asesor legal) no fue para apropiarse para sí o para tercero los caudales de la MPN, sino, fue para reconocer el derecho de los trabajadores producto de los pactos laborales

a) El Ministerio Público no ha probado bajo ninguna forma que los acusados, de manera dolosa, se hayan apropiado o utilizado caudales de la MPM para su beneficio o de terceros ya que el solo hecho de firmar la Resolución de Alcaldía $\mathrm{N}^{\circ}$ 1130-2011 no resulta apropiación o utilización, según la doctrina penal y la jurisprudencia.

b) La emisión de la Resolución de Alcaldía $\mathrm{N}^{\circ} 1130-2011$ y consecuentes memorándum (Memorándum Nº99-2013-MPM-CH-A y Memorándum $\mathrm{N}^{\circ}$ 100-2013-M PM-CH-A) fue con la única finalidad de cumplir con su deber y reconocer los derechos laborales producto del pacto laboral de los trabajadores con la MPM.

6. No se ha podido demostrar la concurrencia del dolo por parte de los acusados (alcalde y asesor legal) para demostrar la concurrencia del delito de peculado.

a) Los magistrados en mayoría se basan en un informe legal externo orientado a determinar la legalidad o ilegalidad de los pagos- para demostrar la concurrencia del dolo en los acusados. Al respecto, es de señalar que no se puede determinar la existencia del dolo en el proceder 
de los acusados solo con un informe legal externo. Sostener esto es muy grave para la dogmática penal y procesal penal e ir en contra de toda la doctrina penal y jurisprudencia penal, tanto en el plano nacional e internacional, que han sostenido lo contrario con respecto a la prueba del dolo.

b) El dolo no se puede probar mediante un informe legal externo. Sostener eso es desechar la teoría de la prueba. La única vía para probar el dolo es -como lo señala Ramón Ragués i Valles ${ }^{38}$ - mediante las herramientas teóricas de la teoría del dolo y la teoría de la prueba. Y para construir la teoría completa del dolo no basta con definir los elementos del delito, sino, que es necesario saber cómo debe constatar en el proceso el dato factico del que depende su aplicación.

7. El delito de peculado no se ha consumado como lo señala el órgano colegiado en mayoría.

a) Es de tener en cuenta que para la consumación del delito de peculado doloso se requiere acreditar si hubo un desplazamiento o desmedro patrimonial de los caudales o efectos de la esfera de dominio del Estado a la esfera de dominio personal del funcionario público o de un tercero.

b) En consecuencia, esta modalidad típica de apropiación se configura cuando el agente se apodera, adueña, atribuye, queda, apropia o hace suyo los caudales o efectos del Estado que le han sido confiados en razón de su cargo al interior de la administración pública para que aquel-funcionario o servidor público- pueda percibirlos, custodiarlos. Por el contrario, si no existe apropiación la conducta es atípica según la jurisprudencia nacional.

c) En este sentido, es inconcebible señalar que con la firma de la Resolución de Alcaldía $N^{\circ} 1130-2011$ por parte del acusado se haya consumado el delito de peculado, porque para ello se requiere en hacer suyo o para tercero los caudales o efectos que pertenecen al Estado, apartándolo de la esfera de la función de la administración pública y colocándose en

38 Ragués i Valles, Ramón (2004). Consideraciones sobre la prueba del dolo. En Revista de Estudios de la Jusitica - REJ, N 4, p. 13. 
situación de disponer de los mismos, cosa que no ha sucedido en el presente caso, porque: primero, con la firma de la mencionada resolución, automáticamente, no se realizaron los pagos, sino mediante exhortos a los funcionarios competentes; y, segundo, el reconocimiento de los aumentos de pagos y reintegros no fue para apropiarse de los caudales, sino, para reconocer los derechos laborales de los trabajadores producto del pacto laboral.

8. Las declaraciones de los testigos son absurdas. Estas declaraciones no acreditan la comisión del delito de peculado porque en dichas declaraciones solo dan cuenta de los procedimientos administrativos realizados, en ningún momento declaran conocer de la existencia de un contubernio criminal entre los acusados y los dieciocho trabajadores para apropiarse de los caudales de la MPM. Estas declaraciones, al ser tomadas como medio de prueba tal cual, por los magistrados en mayoría, vulneran el derecho fundamental a la debida motivación de las resoluciones judiciales.

\section{Dr. Soto Llerena, Valentín}

vsotol@unp.edu.pe

Abogado con más de 20 años de experiencia profesional. Doctor en Derecho y Ciencias Políticas; y Magíster en Derecho con mención en Derecho Civil y Comercial por la Universidad Nacional de Piura; con especialidad en Justicia Constitucional y Derechos Humanos por la Universidad de Pisa (Italia).

Se ha desempeñado diferentes cargos en el sector público y privado. Además, es docente en derecho comercial, civil y penal para el pre grado y posgrado en la Universidad Nacional de Piura. También ha participado como ponente en diferentes eventos organizados por instituciones públicas y privadas a nivel nacional. 